\title{
Article
}

\section{Determination of avermectins residues in soybean, bean and maize using a QuEChERS-based method and ultra-high- performance liquid chromatography coupled to tandem mass spectrometry}

\author{
Fernanda Uczay, Nelson M.G. Bandeira, Luana Floriano, Osmar D. Prestes, Martha B. Adaime, Renato Zanella*
}

\begin{abstract}
Laboratory of Pesticide Residue Analysis (LARP), Chemistry Department, Federal University of Santa Maria, 97105-900 Santa Maria-RS, Brazil; fernanda.uczay@gmail.com (F.U.); nelson.bandeira@live.com (N.M.G.B.); luanaflorianoqmc@gmail.br (L.F.); osmar.prestes@ufsm.br (O.D.P.); adaime@ufsm.br (M.B.A.)

* Correspondence: renato.zanella@ufsm.br
\end{abstract}

\begin{abstract}
Soybean, maize and bean are crops of great economic importance, but in the last years suffered with infestations of the caterpillar Helicoverpa armigera, being the main problem the resistance of this pest to most pesticides. Avermectin emamectin benzoate was recently released to control this pest. Other avermectins, like abamectin, doramectin, eprinomectin and ivermectin are used in large scale because they potent acaricidal, anthelmintic, and insecticidal activities. Thus, a simple and fast method for the determination of avermectins in these crops based on a quick, easy, cheap, effective, rugged and safe (QuEChERS) extraction procedure and ultra-high performance liquid chromatography with tandem mass spectrometry (UHPLC-MS/MS) analysis was developed and validated. For extraction, water followed by acetonitrile:isopropanol and a partition step with salts was stablished. With the clean-up step using activated EMR-Lipid, limits of detection of $1.2 \mu \mathrm{g}$ $\mathrm{kg}^{-1}$ for abamectin, doramectin, emamectin benzoate and ivermectin, and of $2.4 \mu \mathrm{g} \mathrm{kg-1}$ for eprinomectin were achieved. Accuracy and precision evaluated at low levels presented satisfactory results. The method was successfully applied in commercial samples and is a good alternative for routine analysis.
\end{abstract}

Keywords: Macrocyclic lactones; agricultural crops; food; sample preparation; UHPLC-MS/MS

\section{Introduction}

Soybean (Glycine max) is among the most important crops in the world and their demand increases every year, as long as soybean may be applied for animal feed and biodiesel production to raw material for cosmetics [1]. Maize (Zea mays) also has its economic importance related to various forms of use, from animal feed to high technology industry. Common bean (Phaseolus vulgaris), an oleaginous crop such as soybean, is an important source of protein.

Avermectins are a family of natural products with a large macrocyclic lactone ring consisting of four major components (A1a, A2a, B1a and B2a) and four minor components (A1b, A2b, B1b and B2b) isolated from the fermentation broth of Streptomyces avermectinius. Abamectin, doramectin, emamectin benzoate, eprinomectin and ivermectin are avermectins used in large scale because they present potent acaricidal, anthelmintic, and insecticidal activities [2,3]. As an example, abamectin is a blend of 
avermectin B1a $(\geq 80 \%)$ and B1b $(\leq 20 \%)$, and emamectin benzoate, a novel avermectin derivative developed as a pesticide, is a mixture of $\mathrm{B} 1 \mathrm{a}(\geq 90 \%)$ and emamectin $\mathrm{B} 1 \mathrm{~b}(\leq 10 \%)$.

In 2013, the first attacks of Helicoverpa armigera were reported on soybean and bean crops [4]. This caterpillar affects several crops, such as soybean, bean, cotton, chickpea, tomato, eggplant, canola and sunflower. In general, this pest is controlled by the use of insecticides, especially carbamates, organochlorines, organophosphates and pyrethroids. However, due to extensive use of these pesticides, the caterpillar developed resistance against them, causing great damages in the crops [5]. Thus, a phytosanitary emergency was declared in Brazil, and the use of emamectin benzoate was released on an emergency basis. From the class of avermectins, only the use of abamectin as a pesticide was initially allowed in soybean, bean and maize crops [6]. The need for using emamectin benzoate led to the inclusion of this compound in the list of priority analysis pesticide for registration being officially authorized in Brazil in 2017 for use in soybean, bean, maize and cotton.

The maximum residue limits (MRL) values for abamectin and emamectin benzoate in soybean, maize and bean established in Brazil, European Union, USA and by the Codex Alimentarius are, in general, in the range of 5 to $15 \mu \mathrm{g} \mathrm{kg}^{-1}$, with the exception of abamectin in beans $\left(80 \mu \mathrm{g} \mathrm{kg}^{-1}\right)$ established by the Codex Alimentarius.

In recent years, ultra-high performance liquid chromatography coupled with mass spectrometry has been a preferred technique for the determination of pesticides and veterinary drugs in food samples $[7,8]$. However, the determination in complex matrices with high fat, sugar and protein content requires special attention in the sample preparation stage, in order to obtain extracts with low concentration of interferents and containing the analytes of interest [9].

As extraction techniques for determination of pesticide residues in cereals and oleaginous crops we can mention the QuEChERS method, which stands for quick, easy, cheap, effective, rugged and safe [10] and the matrix solid-phase dispersion (MSPD) [11]. Huang et al. [12] analyzed abamectin and ivermectin in olive, soybean, maize and peanut oils and in lard after liquid-liquid extraction (LLE). The extractive solvent used was nhexane, followed by addition of acetonitrile while maintaining vortexing. Macedo et al. [13] analyzed abamectin, doramectin and ivermectin in butter using LLE at high temperatures and a mixture of acetonitrile, ethyl acetate and water $(90: 4: 6, \mathrm{v} / \mathrm{v} / \mathrm{v})$ as solvent.

López-Blanco et al. [14] used a modified QuEChERS method for the multiresidue analysis of abamectin and other pesticides in avocado and olive oil. Several sorbents were tested for the clean-up step. Du et al. [15] established a QuEChERS method, with a cleanup step using primary secondary amine (PSA), to analyze residues of avermectins, pyriproxyfen and diflubenzuron in mushrooms. Liu et al. [16] developed a QuEChERS method for multiresidue determination of pesticides, including abamectin, in grains, with water addition before extraction with acetonitrile. Wang et al. [17] analyzed abamectin, emamectin benzoate and other pesticides in soybean applying a modified QuEChERS acetate method. Thus, giving the importance of avermectins residue analysis in soybean, 
bean and maize crops, the aim of this work was to develop a suitable method for determination of residues of the avermectins abamectin, doramectin, emamectin benzoate, eprinomectin and ivermectin in soybean, maize and bean crops using the same sample preparation step in order to simplify the execution in routine analyses. To the best of our knowledge, there are no methods available in the literature for the determination of avermectins residues in more than one cereals or legumes matrix.

\section{Materials and Methods}

\subsection{Standards, Chemicals and Materials}

Analytical standards of abamectin, doramectin, emamectin benzoate, eprinomectin and ivermectin with purities from 95.0 to $98.3 \%$ were purchased from Dr. Ehrenstorfer (Augsburg, Germany). Sulfadimetoxina-d6, used as surrogate standard (SS) and dimetridazol-d3 used as internal standard (IS) were purchased from Witega Laboratorien Berlin-Adlershof GmbH (Berlin, Germany). Individual stock standard solutions (1000 mg $\mathrm{L}^{-1}$ ) of the analytes were prepared in acetonitrile HPLC grade considering the purity of solid standard. From the stock solutions, new individual solutions at $10 \mathrm{mg} \mathrm{L}^{-1}$ were prepared and kept at $-20^{\circ} \mathrm{C}$. Methanol, acetonitrile and magnesium sulfate were obtained from JT Baker (Phillipsburg, USA). Isopropanol, ammonium formate, formic acid, trisodium citrate dihydrate, sodium hydrogencitrate sesquihydrate and sodium chloride were purchased from Sigma-Aldrich (St. Louis, USA). Ultrapurified water $(18 \mathrm{M} \Omega \mathrm{cm})$ was obtained from a Millipore Milli-Q ${ }^{\circledR}$ system (Molsheim, France). Nylon filters (0.22 $\mu \mathrm{m})$, silica, Florisil ${ }^{\circledR}$, Primary Secondary Amine (PSA) and EMR-Lipid were from Agilent Technologies (Santa Clara, USA). The sorbents C18 and Z-Sep+ were from Supelco (Bellefonte, PA, USA).

For method development, soybean, bean and maize blank samples were obtained from controlled experiments without use of pesticides. None of the evaluated pesticides were detected. Sample were processed for $1 \mathrm{~min}$ in a IKA A11 Basic (Staufen, Germany) analytical mill.

\subsection{UHPLC-MS/MS Parameters}

Analysis were performed in a UHPLC-MS/MS system from Waters (Milford, USA) consisting in an Acquity UPLC ${ }^{\mathrm{TM}}$ binary pump liquid chromatography with Xevo TQ ${ }^{\mathrm{TM}}$ MS/MS triple quadrupole detector, autosampler and column temperature controller. The

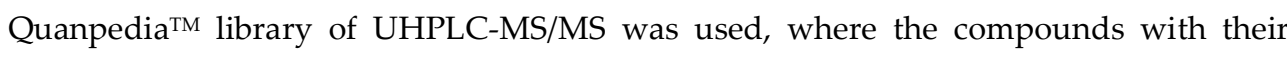
respective precursor and product ions, as well as energies applied to cone and collision, were set. The aqueous phase (mobile phase A) with $10 \mathrm{mmol} \mathrm{L}^{-1}$ of ammonium formate was maintained in all tests. Two organic mobile phase B were evaluated: methanol 1\% $(\mathrm{v} / \mathrm{v})$ formic acid and acetonitrile $0.1 \%(\mathrm{v} / \mathrm{v})$ formic acid. Three chromatographic columns were tested: Acquity $\mathrm{UPLC}^{\mathrm{TM}} \mathrm{BEH} \mathrm{C}_{18}(50 \times 2.1 \mathrm{~mm}, 1.7 \mu \mathrm{m})$ and Acquity UPLC $^{\text {TM }}$ HSST3 $(100 \times 2.1 \mathrm{~mm}$ i.d., $1.8 \mu \mathrm{m})$ from Waters (Wexford, Ireland), and Zorbax Eclipse Plus ${ }^{\circledR}$ C18 $(100 \times 2.1 \mathrm{~mm}, 1.8 \mu \mathrm{m})$ from Agilent Technologies (Santa Clara, USA). The mobile phase operated in gradient mode, started at $50 \% \mathrm{~B}$ and remained constant for 
$1 \mathrm{~min}$, increasing for $2 \mathrm{~min}$ to reach $80 \% \mathrm{~B}$ and then increases to $100 \% \mathrm{~B}$, remaining for 0.5 min, and returning to $50 \% \mathrm{~B}$ maintaining constant until the end of the analysis. The flow rate was $0.225 \mathrm{~mL} \mathrm{~min}{ }^{-1}$, with $10 \mu \mathrm{L}$ of injection volume. The mass spectrometer was operated using selected reaction monitoring (SRM) mode. The electrospray ionization operated in positive mode (ESI+). The transition with the highest intensity was selected for quantification, and the transition with the second highest intensity was used for identification. The following conditions were used for the ESI source: desolvation and cone gas flow rate were set at 500 and $60 \mathrm{~L} \mathrm{~N}_{2} \mathrm{~h}^{-1}$, respectively; the capillary voltage at 2.5 $\mathrm{V}$; desolvation temperature at $350{ }^{\circ} \mathrm{C}$ and source temperature at $150{ }^{\circ} \mathrm{C}$. The collision gas

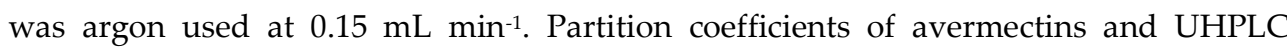
parameters for the determination of their residues in soybean, bean and maize are presented in Table 1.

Table 1. Partition coefficients of avermectins and UHPLC parameters for the determination of their residues in soybean, bean and maize.

\begin{tabular}{|c|c|c|c|c|c|c|c|}
\hline \multirow{2}{*}{ Compounds } & \multirow{2}{*}{$\begin{array}{l}\text { Log } \\
\text { Kow }\end{array}$} & \multirow{2}{*}{$\begin{array}{c}\mathrm{tR}_{\mathrm{R}} \\
(\mathrm{min})\end{array}$} & \multirow{2}{*}{$\begin{array}{l}\text { Precursor } \\
\text { ion }\end{array}$} & \multirow{2}{*}{$\begin{array}{l}\text { Cone } \\
(\mathrm{eV})\end{array}$} & \multicolumn{2}{|c|}{ SRM transitions, $m / z$ (collision energy, $\mathrm{eV}$ ) } & \multirow{2}{*}{$\begin{array}{l}\text { Ion } \\
\text { ratio }\end{array}$} \\
\hline & & & & & Quantification & Identification & \\
\hline Abamectin & 4.0 & 2.83 & {$\left[\mathrm{M}+\mathrm{NH}_{4}\right]^{+}$} & 20 & $890.6>567.4(11)$ & $890.6>305.2(25)$ & 0.91 \\
\hline Doramectin & 4.0 & 3.02 & {$\left[\mathrm{M}+\mathrm{NH}_{4}\right]^{+}$} & 15 & $916.6>331.2(23)$ & $916.6>219.1(25)$ & 0.81 \\
\hline Emamectin & 3.0 & 2.23 & {$[\mathrm{M}+\mathrm{H}]^{+}$} & 40 & $886.6>158.0(37)$ & $886.6>126.0(38)$ & 0.62 \\
\hline Eprinomectin & 5.4 & 2.72 & {$[\mathrm{M}+\mathrm{H}]^{+}$} & 15 & $914.5>186.0(35)$ & $914.5>144.0(20)$ & 0.67 \\
\hline Ivermectin & 3.2 & 3.23 & {$\left[\mathrm{M}+\mathrm{NH}_{4}\right]^{+}$} & 15 & $892.6>569.4(14)$ & $892.6>551.4(25)$ & 0.42 \\
\hline
\end{tabular}

$\mathrm{K}_{\mathrm{ow}}=\mathrm{octanol} /$ water partition coefficient; $\mathrm{t}_{\mathrm{R}}=$ retention time; $\mathrm{SRM}=$ selected reaction monitoring

\subsection{Optimized Sample Preparation Procedure}

The proposed sample preparation method for determination of avermectin residues in soybean, bean and maize is based on the citrate QuEChERS procedure using $5 \mathrm{~g}$ of sample weighed in a 50-mL polypropylene (PP) tube followed by addition of $10 \mathrm{~mL}$ of water and homogenization for $1 \mathrm{~min}$ in ultra-turrax IKA T25 Digital (Staufen, Germany) at high speed to produce a slurry. Extraction was done with $10 \mathrm{~mL}$ of a mixture of acetonitrile:isopropanol 9:1 (v/v) vortexed for $1 \mathrm{~min}$. Partition and salting-out effect were achieved by adding $2 \mathrm{~g}$ of $\mathrm{MgSO}_{4}, 0.5 \mathrm{~g}$ of $\mathrm{NaCl}, 0.5 \mathrm{~g}$ of $\mathrm{C}_{6} \mathrm{H}_{5} \mathrm{Na}_{3} \mathrm{O}_{7} .2 \mathrm{H}_{2} \mathrm{O}$ and $0.25 \mathrm{~g}$ of $\mathrm{C}_{6} \mathrm{H}_{6} \mathrm{Na}_{2} \mathrm{O}_{7} .1 .5 \mathrm{H}_{2} \mathrm{O}$ followed by vortex shaking for $1 \mathrm{~min}$. Tubes were then centrifuged at $4850 \mathrm{~g}$ for $8 \mathrm{~min}$ at $5^{\circ} \mathrm{C}$. Then, $2 \mathrm{~mL}$ of supernatant was transferred to a $15-\mathrm{mL}$ PP tube with $400 \mathrm{mg}$ of EMR-Lipid previously activated with $2 \mathrm{~mL}$ ultrapure water according to Agilent Technologies Protocols [18], vortexed for $1 \mathrm{~min}$, and centrifuged at 10,200g for 8 min at $5{ }^{\circ} \mathrm{C}$. Afterthat, a final step to remove water exccess the extract was transfered to another tube containing $640 \mathrm{mg}$ of $\mathrm{MgSO}_{4}$ and $160 \mathrm{mg}$ of $\mathrm{NaCl}$, vortexed for $1 \mathrm{~min}$, and centrifuged at $10,200 \mathrm{~g}$ for $8 \mathrm{~min}$ at $5^{\circ} \mathrm{C}$. The cleaned extract was filtered in $0.22-\mu \mathrm{m}$ nylon filters and diluted 1:1 (v/v) in the initial composition of the mobile phase for analysis by UHPLC-MS/MS. 


\subsection{Evaluation of the Different QuEChERS Procedures}

The initial tests consisted in the evaluation of the three QuEChERS versions: original [19], citrate [20] and acetate [21] using amounts of sample, solvent and partition salts established in each version. Considering the low percentage of moisture, it was necessary to prepare a slurry using a ultra-turrax. Different ratio matrix:water $(\mathrm{m} / \mathrm{v})$ of $1: 1 ; 1: 1.5$ and 1:2 were evaluated. Blank samples of soybean, bean and maize spiked at $20 \mu \mathrm{g} \mathrm{kg-1}$ and matrix matched calibration curves at 1, 2, 5, 10 and $20 \mu \mathrm{g} \mathrm{L}^{-1}$, corresponding to 4, 8, 20, 40 and $80 \mu \mathrm{g} \mathrm{kg}^{-1}$, were used for evaluation of the different extraction procedures.

After some tests, the QuEChERS citrate was selected for evaluation of diferrent extraction solvents: acetonitrile and acetonitrile:isopropanol in the proportions 9:1, 8:2 and 7:3 (v/v). To perform the evaluations, $5 \mathrm{~g}$ of sample were weighed in 50-mL PP tube with $10 \mathrm{~mL}$ of ultrapurified water and the content was homogenized in ultra-turrax for $1 \mathrm{~min}$. Then, $10 \mathrm{~mL}$ of the different extraction solvents was added and tubes were vortexed for 1 min. Afterthat, $2 \mathrm{~g}$ of $\mathrm{MgSO}_{4}, 0.5 \mathrm{~g}$ of $\mathrm{NaCl}, 0.5 \mathrm{~g}$ of $\mathrm{C}_{6} \mathrm{H}_{5} \mathrm{Na}_{3} \mathrm{O}_{7} .2 \mathrm{H}_{2} \mathrm{O}$ and $0.25 \mathrm{~g}$ of $\mathrm{C}_{6} \mathrm{H}_{6} \mathrm{Na}_{2} \mathrm{O}_{7} .1 .5 \mathrm{H}_{2} \mathrm{O}$ were added, tubes were vortexed for $1 \mathrm{~min}$ and centrifuged at $4850 \mathrm{~g}$ for $8 \mathrm{~min}$ at $5^{\circ} \mathrm{C}$. The supernatant $(2 \mathrm{~mL})$ was submitted to a clean-up step by d-SPE with $250 \mathrm{mg}$ of C18, $50 \mathrm{mg}$ of PSA and $300 \mathrm{mg}$ of $\mathrm{MgSO}_{4}$ followed by centrifugation at 10,200 $g$ for $8 \mathrm{~min}$ at $5^{\circ} \mathrm{C}$.

\subsection{Evaluation of Different Clean-up Conditions}

An aliquot of $2 \mathrm{~mL}$ of extract was submitted to different d-SPE clean-up conditions with the following materials: $250 \mathrm{mg}$ of C18, $50 \mathrm{mg}$ of PSA; $100 \mathrm{mg}$ Z-Sep+; $400 \mathrm{mg}$ silica; $400 \mathrm{mg}$ Florisil $^{\circledR} ; 400 \mathrm{mg}$ EMR-Lipid activated with $2 \mathrm{~mL}$ ultrapurified water. The samples were centrifuged at $10,200 \mathrm{~g}$ for $8 \mathrm{~min}$ at $5{ }^{\circ} \mathrm{C}$. Only for the assay using EMR-Lipid, a complementar step was included where $2 \mathrm{~mL}$ of supernatant was transferred to another tube with $640 \mathrm{mg}$ of $\mathrm{MgSO}_{4}$ and $160 \mathrm{mg}$ of $\mathrm{NaCl}$ as recommended by the product protocol. Extracts were centrifuged again at $10,200 \mathrm{~g}$ for $8 \mathrm{~min}$ at $5^{\circ} \mathrm{C}$, filtred through $0.22-\mu \mathrm{m}$ nylon filters and diluted 1:1 (v/v) in mobile phase for analysis.

\subsection{Validation Procedure}

After evaluating the sample preparation procedure for determination of avermectin residues in soybean, bean and maize, the method was validated according to SANTE guidelines [22]. The following parameters were evaluated: selectivity, matrix effect, analytical curve and linearity, limits of detection (LOD) and quantification (LOQ), precision (repeatability and intermediate precision) and accuracy. The selectivity of the method was evaluated by comparing the chromatograms obtained in the UHPLC-MS/MS system by injections of the blank sample extracts and spiked blank samples for each of the studied matrices. Calibration curves were prepared in acetonitrile, blank sample extract and blank matrix at $1.0 ; 2.0 ; 5.0 ; 10.0$ and $20.0 \mu \mathrm{g} \mathrm{L}^{-1}$ for each of the studied matrices. The LOQ was considered to be the lowest spiked concentration, which presented signal/noise ratio higher than 10 , recoveries between $70-120 \%$, with relative standard deviation (RSD) $\leq 20 \%$. The LOD was established dividing the LOQ by 3.33 . The accuracy and precision 
(repeatability and intermediate precision) of the method was evaluated through recovery assays. Spiked blank samples of each studied matrix at 4, 8, 20, 40 and $80 \mu \mathrm{gg}^{-1}$ in replicates $(n=5)$ were prepared to evaluate accuracy and precision. The matrix effect was evaluated for the three matrices under study comparing the slopes of the analytical curves in solvent and in the blank matrix extract.

\subsection{Application in Real Samples}

The developed and validated method was applied for the determination of residues of the avermectins under study in 18 soybean samples, 12 bean samples and 15 maize samples obtained from supermarkets from the Rio Grande do Sul State, Brazil. Each commercial sample of at least $1 \mathrm{~kg}$ was collected, milled and stored in a freezer at $-20^{\circ} \mathrm{C}$.

\section{Results}

\subsection{UHPLC-MS/MS Analysis}

The ionization of avermectins was performed with electrospray in positive mode (ESI+). The composition of the mobile phase may significantly influence the analytical signal and the proper separation of the analytes [23]. The mobile phase (A) aqueous solution ammonium formate $10 \mathrm{mmol} \mathrm{L}^{-1}$ and (B) methanol $0.1 \%$ formic acid was chosen due to the higher analytical signal obtained for the compounds under study. The selected mobile phase additives favored the formation of $\left[\mathrm{M}+\mathrm{NH}_{4}\right]^{+}$adducts used for the detection of abamectin, doramectin and ivermectin after the chromatographic separation. The formation of the ion $[\mathrm{M}+\mathrm{H}]^{+}$, used for emamectin benzoate and eprinomectin, was favored by the addition of formic acid. The addition of acids also reduce the formation of $[\mathrm{M}+\mathrm{Na}]^{+}$ adducts. The sodium adducts are avoided due to its high stability and poor fragmentation response [24]. The column Acquity UPLC ${ }^{\mathrm{TM}}$ BEH $\mathrm{C}_{18}$ provided high resolution and good peak shape for the compounds under study. Still, the chromatographic column chosen is the same used in routine analysis in our laboratory.

\subsection{Sample Preparation Evaluations}

Soybean and bean are considered complex matrices due to the high amount of fats and proteins, besides having a low humidity, needing to add water for the extraction. Maize presents a low percentage of water and a particular characteristic that is the presence of starch, which increases its complexity. The preparation of slurry was uniformized for the proportion 1:2 of sample:water which produced suitable consistence. This proportion of sample:water was reported for low moisture matrices like maize [25], wheat and oat [26], and barley and wheat [27]. Lower protortions of water of 1:1 and 1:1.5 were not effective to have a homogeneous slurry.

Considering the main objective of developing an effective and unified sample preparation procedure for determination of avermectin residues in soybean, bean and maize, the evaluation of which of the QuEChERS procedures provides best results for the evaluated matrices was performed. The three most common QuEChERS procedures using acetonitrile as extraction solvent have not been effective for the extraction of the avermectins from the selected matrices presenting recoveries ranging from 35 to $101 \%$ and 
RSD between 3 and 37\%. There were no significant differences $(p<0.05)$ between most of the assays. The QuEChERS citrate was chosen for forder investigations due to present the best recovery (64\%) for eprinomectin, that was the compound with lower recoveries in all cases. This result is closer to the acceptance criterion of $70-120 \%$ [22] but an inprovment is required. QuEChERS citrate also presented lower RSD values in comparison to the QuEChERS acetate and original.

As avermectins is a class of chemical compounds with high values of Kow, isopropanol was evaluated in different proportions with acetonitrile trying to improve extraction efficiency. Isopropanol may be used as extraction solvent, besides being commonly used as mobile phase in liquid chromatography. Menezes Filho et al. [28] employed isopropanol in a mixture 8:2 (v/v) with water in the extraction of pesticides from mangoes with satisfactory results for most of the analytes. In addition, Seth et al. [29] considered isopropanol an efficient and advantageous extraction solvent for soybean grains and other oilseeds and an attractive alternative to the frequently used solvents. The extraction solvents acetonitrile and acetonitrile:isopropanol 9:1 (v/v) presented similar results for the extraction of abamectin, doramectin and ivermectin for all matrices, but for emamectin benzoate and eprinomectin the addition of isopropanol improved the extraction efficiency by about $25 \%$. This was very important because emamectin benzoate, that in general presented lower recoveries, with this modification the recoveries were above $70 \%$ for all matrices. Then tests with acetonitrile containing different proportions of isopropanol $(9: 1 ; 8: 2$ and $7: 3, \mathrm{v} / \mathrm{v})$ were performed to evaluate whether there would be a significant increase in the recoveries of the compounds as the volume of isopropanol increased. No considerable variation in recoveries of avermectins for the three matrices were observed with the different proportions of the extraction solvents. However, it was observed that with higher volumes of isopropanol the analytical response decreased for abamectin and eprinomectin. Once, abamectin and eprinomectin are the two compounds with lowest sensitivity in UHPLC-MS/MS analysis, the ratio 9:1 (v/v) for acetonitrile:isopropanol was selected.

\subsection{Clean-up Procedure Evaluations}

In the clean-up step, it was decided to evaluate d-SPE, without considering SPE, in order to keep the QuEChERS advantages. Figure 1 shows recovery results for five sorbents evaluated for soybean. Recoveries above $70 \%$ for most of the compounds were obtained. Similar resuts were observed for bean and maize. The use of C18+PSA presented the lowest recoveries, with a mean recovery $<70 \%$ for abamectin $(69 \%)$, ivermectin $(63 \%)$ and doramectin (64\%), while abamectin presented RSD > 20\%. Regarding the EMR-Lipid and Florisil ${ }^{\circledR}$, the five compounds presented adequate recoveries and RSD. Results for Z-Sep+ were satisfactory, except for eprinomectin in which presented recovery of $67 \%$. Silica presented recoveries $>70 \%$ for all compounds, however the RSD for abamectin was $>20 \%$. 

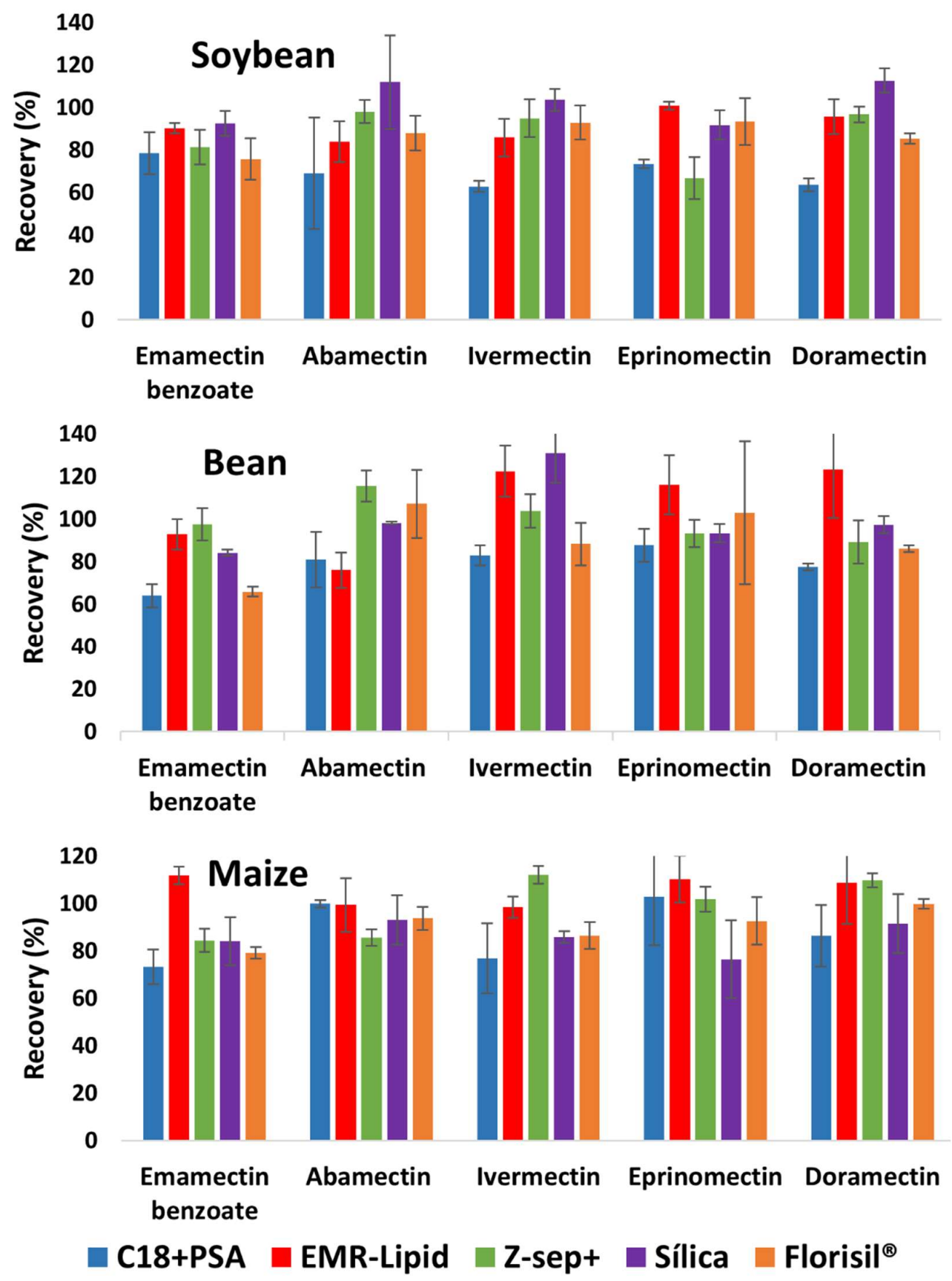

Figure 1. Recoveries obtained with d-SPE clean-up for soybean, bean and maize extracts using different sorbents

The clean-up with C18 + PSA, EMR-Lipid, Silica and Florisil ${ }^{\circledR}$ presented for some compounds recoveries $<70 \%$ and $>120 \%$, especially for bean. The use of C18 + PSA resulted in the lowest recoveries in comparison to the other sorbents, and emamectin benzoate had only a recovery of $64 \%$. EMR-Lipid showed all recoveries above $70 \%$, with ivermectin and doramectin showing $122 \%$ and $123 \%$, respectively. Silica had a mean recovery of $131 \%$ for ivermectin and Florisil ${ }^{\circledR}$ achieved a mean recovery of $66 \%$ for 
emamectin benzoate and a RSD of more than 30\% for eprinomectin. Z-Sep+ was the only sorbent that presented recoveries between $70-120 \%$. For maize, all sorbents evaluated presented satisfactory recoveries (70 to $120 \%$ ). The RSD was satisfactory for all analytes, except for eprinomectin, when using C18 + PSA that presented RSD $>20 \%$. As maize obtained recoveries between $70-120 \%$ for the five sorbents, the values obtained for soybean and bean were taken into account to select the most suitable sorbent. C18 + PSA was discarded because of the lowest recovery values in comparison to the other sorbents for both matrices. The claen-up that generated the best results for bean was Z-Sep+ and for soybean was EMR-Lipid. In general, EMR-Lipid presented lighter advantage in terms of recovery and RSD, as well the final extract presented less coextractives when evaluated by gas chromatography-mass spectrometry in full scan mode.

The non-activated EMR-Lipid was tested in the clean-up step to verify if it would have better results or similar to the activated one. As a result, the non-activated presented higher recoveries for abamectin, emamectin benzoate and ivermectin, compared to the activated EMR-Lipid. For eprinomectin the recovery was similar, but doramectin presented a much lower recovery. However, the RSD values for the five compounds increased (RSD $>20 \%$ ) with the use of non-activated EMR-Lipid. With activated EMRLipid the RSD were $<10 \%$ for all avermectins. Therefore, the activated EMR-Lipid was chosen for use in the clean-up step of the three matrices.

\subsection{Validation Results of the Proposed Method}

Matrix-matched calibration was used for all matrices, where linearity was obtained with a determination coefficient $\left(\mathrm{r}^{2}\right)>0.99$ for the five compounds and the levels $1,2,5,10$ and $20 \mu \mathrm{g} \mathrm{L}^{-1}$. In order to evaluate the accuracy of the method, recovery tests were performed at five concentration levels $\left(4,8,20,40\right.$ and $\left.80 \mu \mathrm{g} \mathrm{kg}^{-1}\right)$ for each matrix using the modified citrate QuEChERS method and the results were presented in Table 2. The lowest levels of concentration were chosen taking into account the established MRL values.

The proposed method presented adequate accuracy with recovery results between $70-120 \%$ for all compounds, matrices and spike levels, both in repeatability and intermediate precision assays. The precision was also very good, with RSD $<20 \%$ in all cases. The matrix effect is considered to have an influence on the analytical performance when the result is not between -20 and $20 \%$. Therefore, for all compounds in soybean and bean the effect was not significant. For maize, doramectin presented a matrix effect of $22 \%$. In order to compensate the matrix effect, matrix-matched calibration was selected for quantification. Considering that all spike levels presented recoveries from 70 to $120 \%$ and RSD $\leq 20 \%$ for all matrices, the method LOQ was established at $4 \mu \mathrm{g} \mathrm{kg}^{-1}$ and the corresponding method LOD at $1.2 \mu \mathrm{g} \mathrm{kg}{ }^{-1}$. 
Table 2. Maximum Residues Limits, recovery (\%) and relative standard deviation (RSD) (\%) for repeatability and intermediate precision assays, $\mathrm{LOQ}\left(\mu \mathrm{g} \mathrm{kg}^{-1}\right)$ and matrix effects (\%) for each compound in the different matrices

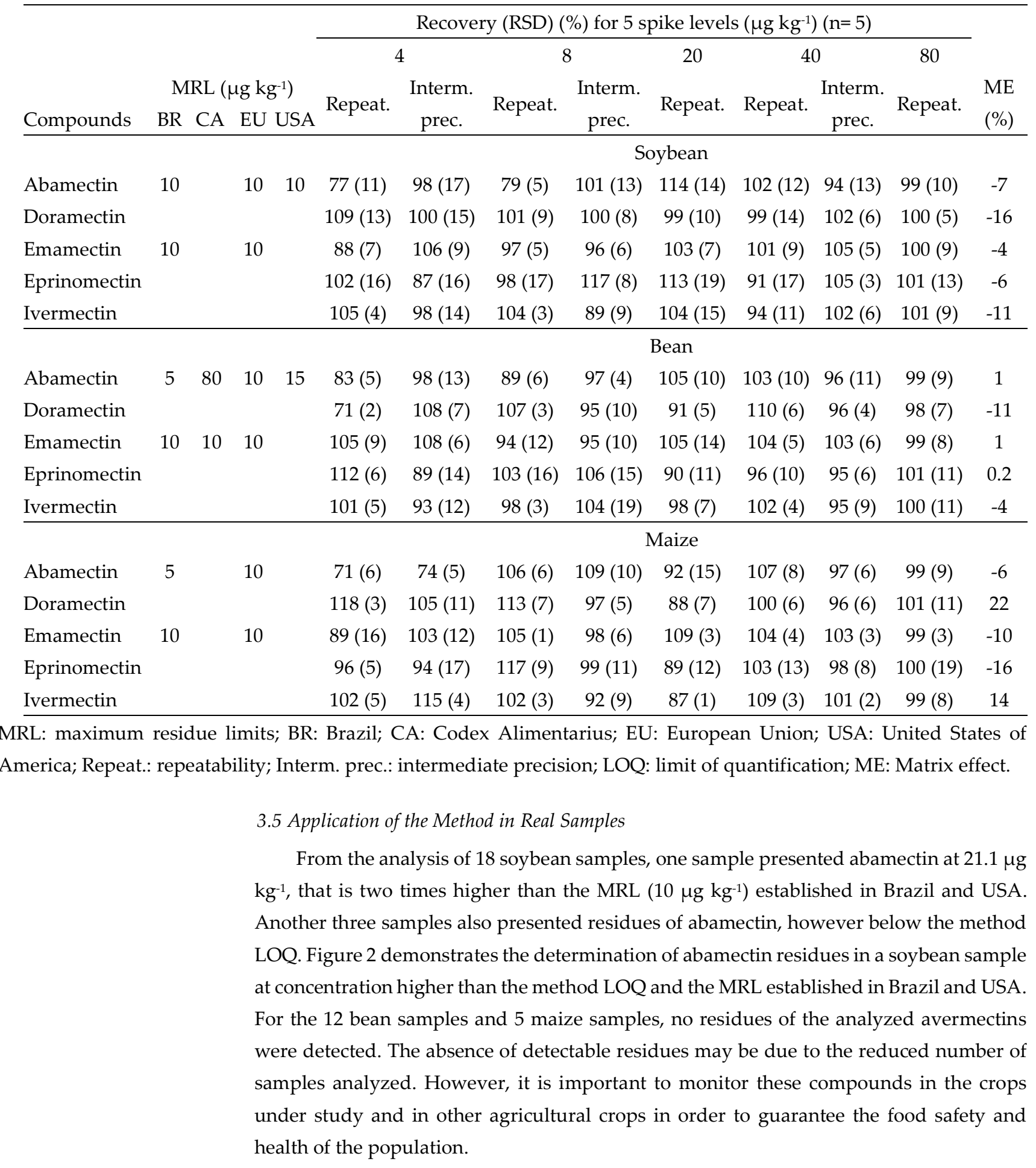




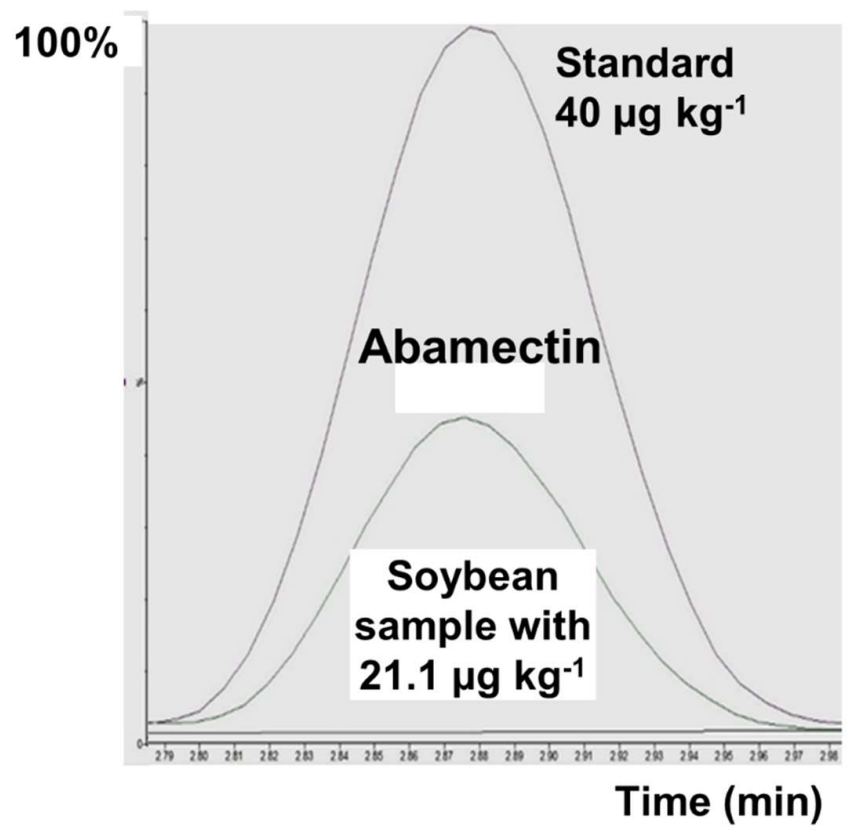

Figure 2. Overlapping of the signal obtained from a positive sample of soybean for abamectin $\left(21.1 \mu \mathrm{g} \mathrm{kg}^{-1}\right)$ and a standard in blank matrix corresponding to $40 \mu \mathrm{g} \mathrm{kg}^{-1}$.

\section{Conclusions}

The results obtained with the modifications of the QuEChERS citrate method indicate good efficiency of the proposed method for the determination of avermectins residues in soybean, bean and maize samples. The addition of isopropanol to the acetonitrile improved the extraction efficiency and the clean-up step using EMR-Lipid permitted to obtain clean extracts, avoiding the need of frequent maintenance of the UHPLC-MS/MS system. The use of UHPLC-MS/MS with additives in the mobile phase and specific conditions allowed the determination with method limits of quantification below the MRL values. The validation indicated very good results of accuracy and precision, proving that the proposed method is reliable. The method was efficiently applied to real samples with positive results, including with abamectin in a soybean at concentration higher than the MRL established in Brazil and USA. We emphasize that there are no available studies reporting the development of a method for the determination of avermectins in more than one agricultural crop, highlighting the relevance of this work. The proposed modified QuEChERS citrate method for determination of avermectins in soybean, bean and maize using UHPLC-MS/MS was effective and is a good alternative for routine laboratories.

Author Contributions: Conceptualization, R.Z. and O.D.P.; methodology, F.U., N.M.G.B and O.D.P.; validation, F.U., N.M.G.B and L.F.; formal analysis, F.U., N.M.G.B and L.F.; investigation, F.U.; resources, F.U.; writing - original draft preparation, F.U., N.M.G.B and L.F.; writing-review and editing, R.Z and M.B.A.; supervision, O.D.P.; project administration, R.Z.; funding acquisition, R.Z and M.B.A. All authors have read and agreed to the published version of the manuscript.

Funding: This research was funded by the Conselho Nacional de Desenvolvimento Científico e Tecnológico (CNPq), grant number 312207/2016-6.

Institutional Review Board Statement: Not applicable.

Informed Consent Statement: Not applicable.

Conflicts of Interest: The authors declare no conflict of interest. The funder had no role in the design of the study; in the collection, analyses, or interpretation of data; in the writing of the manuscript; or in the decision to publish the results. 


\section{References}

1. Romanato, F. N.; Hamawaki, O. T.; Sousa, L. B. de.; Nogueira, A. P. O.; Neto, D. P. de C.; Borges, C. C. R.; Hamawaki, C. D. L.; Hamawaki, R. L. Parametric and non-parametric analysis for determining the adaptability and stability of soybean genotypes in three sowing periods. Biosci. J. 2016, 32, 574-580. DOI: 10.14393/BJ-v32n3a2016-26078

2. Zhang, J.; Nan, X.; Yu, H-T.; Cheng, P-L.; Zhang, Y.; Liu, Y-Q.; Zhang, S-Y.; Hu, G-F.; Liu, H.; Chen, A-L. Synthesis, biological activities and structure activity relationships for new avermectin analogues. Eur. J. Med. Chem. 2016, 121, 422-432. DOI: 10.1016/j.ejmech.2016.05.056

3. Khalil, M. S.; Darwesh, D. M. Avermectins: the promising solution to control plant parasitic nematodes. J. Plant Sci. Phytopath. 2019, 3, 81-85. DOI: 10.29328/journal.jpsp.1001036

4. Brazil. Brazilian Ministry of Agriculture, Livestock and Supply. Normative Instruction nr. 13. Available online:https://www.infoconsult.com.br/legislacao/instrucao_normativa_mapa/2013/in_mapa_13_2013.htm (accessed on 14 October 2021).

5. Bilal, M.; Freed, S.; Ashraf, M. Z.; Zaka, S. M.; Khan, M. B. Activity of acetylcholinesterase and acid and alkaline phosphatases in different insecticide-treated Helicoverpa armigera (Hübner). Environ. Sci. Pollut. Res. Int. 2018, 25, 22903-22910. DOI: 10.1007/s11356-018-2394-3

6. Bird, L. J.; Drynan, L. J.; Walker, P. W. The use of F2 screening for detection of resistance to emamectin benzoate, chlorantraniliprole, and indoxacarb in australian populations of Helicoverpa armígera (Lepidoptera: Noctuidae). J. Econ. Entomol. 2017, 110, 651-659. DOI: 10.1093/jee/tox037

7. Orso, D.; Floriano, L.; Ribeiro, L. C.; Bandeira, N. M. G.; Prestes, O. D.; Zanella, R. Simultaneous determination of multiclass pesticides and antibiotics in honey samples based on ultra-high performance liquid chromatography-tandem mass spectrometry. Food Anal. Methods 2016, 9, 1638-1653. DOI: 10.1007/s12161-015-0339-8

8. May, M. M.; Ferronato, G.; Bandeira, N. M. G.; Prestes, O. D.; Zanella, R.; Adaime, M. A. Determination of pesticide residues in soy-based beverages using a QuEChERS method with clean-up optimized by central composite design and ultra-highperformance liquid chromatography-tandem mass spectrometry. Food Anal. Methods 2017, 10, 369-378. DOI: 10.1007/s12161-0160593-4

9. Bandeira, N. M. G.; Ribeiro, L. C.; Rizzetti, T. M.; Martins, M. L.; Adaime, M. B.; Zanella, R.; Prestes, O. D. Evaluation of QuEChERS sample preparation for determination of avermectins residues in ovine muscle by HPLC-FD and UHPLC-MS/MS. J. Braz. Chem. Soc. 2017, 28, 878-886. DOI: 10.21577/0103-5053.20160240

10. Musarurwa, H.; Chimuka, L.; Pakade, V. E.; Tavengwa, N. T. Recent developments and applications of QuEChERS based techniques on food samples during pesticide analysis. J. Food Compos. Anal. 2019, 84, 103314. DOI: 10.1016/j.jfca.2019.103314

11. González-Curbelo, M. Á.; Herrera-Herrera, A. V.; Ravelo-Pérez, L. M.; Hernández-Borges, J. Sample-preparation methods for pesticide-residue analysis in cereals and derivatives. Trends Anal. Chem. 2012, 38, 32-51. DOI: 10.1016/j.trac.2012.04.010

12. Huang, J-X.; Lu, D-H.; Wan, K.; Wang, F-H. Low temperature purification method for the determination of abamectin and ivermectin in edible oils by liquid chromatography-tandem mass spectrometry. Chin. Chem. Lett. 2014, 25, 635-639. DOI: 10.1016/j.cclet.2014.01.036

13. Macedo, F.; Marsico, E. T.; Conte-Júnior, C. A.; Resende, M. F. de.; Brasil, T. F.; Netto, A. D. P. Development and validation of a method for the determination of low-ppb levels of macrocyclic lactones in butter, using HPLC-fluorescence. Food Chem. 2015, 179, 239-245. DOI: 10.1016/j.foodchem.2015.01.046

14. López-Blanco, R.; Nortes-Méndez, R.; Robles-Molina, J.; Moreno-Gonzáles, D.; Gilbert-López, B.; García-Reyes, J. F.; MolinaDíaz, A. Evaluation of different cleanup sorbents for multiresidue pesticide analysis in fatty vegetable matrices by liquid chromatography tandem mass spectrometry. J. Chromatogr. A 2016, 1456, 89-104. DOI: 10.1016/j.chroma.2016.06.019

15. Du, P.; Liu, X.; Gu, X.; Dong, F.; Xu, J.; Kong, Z.; Wu, Y.; Zhu, Y.; Li, Y.; Zheng, Y. Rapid residue analysis of pyriproxyfen, avermectins and diflubenzuron in mushrooms by ultra-performance liquid chromatography coupled with tandem mass spectrometry. Anal. Methods 2013, 5, 6741-6747. DOI: 10.1039/c3ay41074a

16. Liu, Z.; Qi, P.; Wang, X.; Wang, Z.; Xu, X.; Chen, W.; Wu, L.; Zhang, H.; Wang, Q.; Wang, X. Multi-pesticides residue analysis of grains using modified magnetic nanoparticle adsorbent for facile and efficient cleanup. Food Chem. 2017, 230, 423-431. DOI: 10.1016/j.foodchem.2017.03.082

17. Wang, J.; Cheung, W.; Chow, W. Ultra-high performance liquid chromatography/ electrospray ionization-tandem mass spectrometry determination of 151 pesticides in soybeans and pulses. J. AOAC Int. 2013, 96, 1114-1133. DOI: 10.5740/jaoacint.12465

18. Agilent Technologies. Enhanced Matrix Removal-Lipid Brochure. 5991-6052EN, 2016.

19. Anastassiades, M.; Lehotay, S.; Štajnbaher, D.; Schenck, F. Fast and easy multiresidue method employing acetonitrile extraction/partitioning and "dispersive solid-phase extraction" for the determination of pesticide residues in produce. J. AOAC Int. 2003, 86, 412-431. DOI: 10.1093/jaoac/86.2.412

20. Anastassiades, M.; Scherbaum, E.; Tasdelen, B.; Stajnbaher, D. Recent developments in QuEChERS methodology for pesticide multiresidue analysis. In: Pesticide Chemistry: Crop Protection, Public Health, Environmental Safety, 1st ed.; Ohkawa, H.M., Hisashi, L., Philip, W., Eds.; Wiley-VCH Verlag GmbH \& Co. KGaA: Weinheim, Germany, 2007; pp. 439-458. DOI: 10.1002/9783527611249.ch46 
21. Lehotay, S. J.; Mastovská, K.; Lightfield, A. R. Use of buffering and other means to improve results of problematic pesticides in a fast and easy method for residue analysis of fruits and vegetables. J. AOAC Int. 2005, 88, 615-629. DOI: 10.1093/jaoac/88.2.615

22. European Commission. SANTE/12682/2019. Guidance Document on Analytical Quality Control and Method Validation Procedures for Pesticides Residues Analysis in Food and Feed. European Commission Directorate-General for Health and Food Safety. $\quad$ (rev.0). 2019. Available online: https://www.eurl-pesticides. eu/userfiles/file/EurlALL/AqcGuidance_SANTE_2019_12682.pdf (accessed on 14 October 2021).

23. Kemmerich, M.; Rizetti, T. M.; Martins, M. L.; Prestes, O. D.; Adaime, M. B.; Zanella, R. Optimization by central composite design of a modified QuEChERS method for extraction of pesticide multiresidue ins sweet pepper and analysis by ultra-highperformance liquid chromatography- tandem mass spectrometry. Food Anal. Methods 2015, 8, 728-739. DOI: 10.1007/s12161-0149951-2

24. Moscou, I. C.; Dasenaki, M. E.; Thomaidis, N. S. Ionization study and simultaneous determination of avermectins and milbemycines in fish tissue by LC-ESI-MS/MS. J. Chromatogr. B Analyt. Technol. Biomed. Life Sci. 2019, 1104, 134-140. DOI: 10.1016/j.jchromb.2018.11.017

25. Marchis, D.; Ferro, G. L.; Brizio, P.; Squadrone, S.; Abete, M. C. Detection of pesticides in crops: a modified QuEChERS approach. Food Control 2012, 25, 270-273. DOI: 10.1016/j.foodcont.2011.10.055

26. Herrmann, S. S.; Poulsen, M. E. Clean-up of cereal extracts for gas chromatography-tandem quadrupole mass spectrometry pesticide residues analysis using primary secondary amine and C18. J. Chromatogr. A 2015, 1423, 47-53. DOI: 10.1016/j.chroma.2015.10.086

27. Francesquett, J. Z.; Rizzetti, T. M.; Cadaval, T. R. S.; Prestes, O. D.; Adaime, M. B.; Zanella, R. Simultaneous determination of the quaternary ammonium pesticides paraquat, diquat, chlormequat, and mepiquat in barley and wheat using a modified quick polar pesticides method, diluted standard addition calibration and hydrophilic interaction liquid chromatography coupled to tandem mass spectrometry. J. Chromatogr. A 2019, 1592, 101-111. DOI: 10.1016/j.chroma.2018.12.060.

28. Menezes Filho, A.; dos Santos, F. N.; Pereira, P. A. P. Development, validation and application of a methodology based on solidphase micro extraction followed by gas chromatography coupled to mass spectrometry (SPME/GC-MS) for the determination of pesticide residues in mangoes. Talanta 2010, 81, 346-354. DOI: 10.1016/j.talanta.2009.12.008

29. Seth, S.; Agrawal, Y. C.; Ghosh, P. K.; Jayas, D. S.; Singh, B. P. N. Oil extraction rates of soya bean using isopropyl alcohol as solvent. Biosys. Eng. 2007, 97, 209-217. DOI: 10.1016/j.biosystemseng.2007.03.008 